\title{
States of Affairs - the Full Picture
}

\section{Uwe Meixner}

\section{What are states of affairs?}

Instead of offering a definition, it seems best to indicate where to look for states of affairs. We are likely to find them when we are sorting through the intentional objects of our intentional experiences, above all the intentional objects of perceptions. Consider: I am looking at a glass on a table. I perceive the glass, I perceive the table. But I also perceive (1) that the glass is on the table; (1) is a state of affairs. And I also perceive (2) that the glass is translucent; (2) is another state of affairs. Moreover, I perceive (3) that nothing else is on the table; (3) is also a state of affairs. Moreover, I immediately perceive (4) that the glass is not a glass designed by $N . N$., but (5) that it is either a glass designed by $N^{\prime} . N^{\prime}$. or by $N^{\prime \prime} . N^{\prime \prime} ;$ (4) and (5), too, are states of affairs.

Perception, however, is not the only place where states of affairs may be found. Person $\mathrm{X}$ hopes (wishes, believes, knows, rejects, accepts, denies, asserts, imagines, fears, thinks it likely, thinks it unlikely, etc.) (6) that $A$. Normally, a singular term of the form "that A" will name a state of affairs. At least, this is a legitimate prima facie assumption. And it need not be accepted without argument: Suppose someone asked, "Which state of affairs among those we have been considering is the most important one?" In most cases, the answer would have the form "The state of affairs that A", or simply "That A". This shows that expressions of the form "that A" are, or function just like, singular terms. One might claim that expressions of the form "[the state of affairs] that A", though singular terms, never refer to what they are supposed to refer to. But this claim, in turn, needs (a lot of) argument. 


\section{How are states of affairs related to propositions?}

The referential device "that A" which forms singular terms from sentences can be used to name both propositions and states of affairs. Indeed, in each instance of its use it can be taken to name both a state of affairs and a proposition if it can be taken to name anything at all - though frequently the two referential functions will not be on equal footing. It is true that some phrases of the form "X Rs that A" do not sound well if "the proposition" is inserted at the left of "that" - for example, "Jack perceives the proposition that the glass is standing on the table"; and it is also true that some phrases of the form "X Rs that A" do not sound well if "the state of affairs" is inserted at the left of "that" - for example, "Jack asserts the state of affairs that the universe is infinite." But, in fact, some phrases of the form "X Rs that A" do not sound well whether one inserts "the proposition" or "the state of affairs" at the left of "that" - for example, "Jack hopes the proposition/the state of affairs that he wins 1 million dollars next year." I propose that one should not take these "sound-effects" too seriously. Why shouldn't one say that a proposition is perceived or a state of affairs asserted, as long as it is possible to connect a meaning with these phrases? Namely: a proposition is perceived if, and only if, it is perceived to be true, and a state of affairs is asserted if, and only if, it is asserted to obtain (and a proposition is hoped if, and only if, it is hoped to be true, whereas a state of affairs is hoped if, and only if, it is hoped to obtain). But it remains true that asserting states of affairs and perceiving propositions implies an analogical, secondary use of the verbs "assert" and "perceive": a proposition is (per analogiam) perceived, and a state of affairs asserted, on the basis of something else being perceived, respectively asserted, in the primary, non-analogical sense of these verbs. In this primary sense, indeed, states of affairs cannot be asserted (while propositions can be), and propositions cannot be perceived (while states of affairs can be).

Though states of affairs and propositions are normally named by the same singular terms - the singular terms of the form "that A" - no state of affairs is a proposition, no proposition a state of affairs: all propositions are either true or false; but no state of affairs is either true or false. The relationship between states of affairs and propositions, to the extent that they are named by "that"-terms, is brought out by the following principle 
(which, by the way, does not imply that there is a one-to-one correspondence between propositions and states of affairs):

P1 The proposition that $A$ is true if, and only if, the state of affairs that $A$ obtains.

For example:

The proposition that snow is white is true if, and only if, the state of affairs that snow is white obtains.

Another contrast between states of affairs and propositions is that all propositions are abstract entities, whereas at least some states of affairs are concrete entities. Even without delving deeply into the abstract-concrete distinction, it is plain that it is legitimate to interpret the term "the world" in a non-metaphorical sense to designate a certain comprehensive state of affairs (and, as everyone knows, Wittgenstein used that interpretation in the Tractatus). But the world is clearly not an abstract entity - in whatever non-metaphorical sense of the term "the world" may be understood. Hence at least one state of affairs is not abstract. There are, however, other examples of concrete states of affairs: the state of affairs that the moon revolves round the earth, the state of affairs that ice is lighter than water, etc. These states of affairs are concrete, while the corresponding propositions - the proposition that the moon revolves around the earth, and the proposition that ice is lighter than fluid water - are abstract. In general, propositions are abstract - hence objective, not subjective - representations of states of affairs; ${ }^{1}$ this is what their being consists in.

It should be noted that the paradigm cases of concrete entities - physical individuals - do never occur without being embedded in a physical state of affairs, and in fact cannot occur otherwise. Now, is it that a physical state of affairs derives its physicalness from the physicalness of the physical individual(s) that is (are) embedded in it, or is it rather the other way round?

\footnotetext{
${ }^{1}$ Representations for whom? For us human beings, of course. Note that though a representation is sometimes objective (not subjective: not in the mind), it is always a representation for someone.
} 
It seems to me indeed that it is the other way round. In any case: there can be no doubt that there are physical states of affairs, and since, for analytical reasons, everything physical is concrete, it follows that there are concrete states of affairs. Some concrete states of affairs are therefore made concrete by being physical. Physicalists would say that all concrete states of affairs are made concrete by being physical, since they believe that concrete and physical coincide. It seems to me, on the contrary, that they do not coincide. But I leave this an open question, for it leads us too far afield.

States of affairs are in a rather robust sense ontologically prior to propositions, since the proposition that $A$, if it is true, is always true because the state of affairs that $A$ obtains; despite the fact that $\mathrm{P} 1$ is a biconditional, it is never the other way around: that the state of affairs that $A$ obtains because the proposition that $A$ is true. It is also apparent that propositions are more fine-grained than states of affairs: the proposition that Jack is older than Mack is different from the proposition that Mack is younger than Jack; but the state of affairs that Jack is older than Mack is certainly the same state of affairs as the state of affairs that Mack is younger than Jack. Both of these last-mentioned ontological data confirm the hypothesis, asserted above, that propositions are abstract objective representations of states of affairs. As such, they have, moreover, a quasi-sentential nature. For, besides being representations of states of affairs, propositions are expressed by true or false sentences, and the semantical relation of expression is of such a kind that, ontologically, the expressee (if I may say so) is rather close to the expresser.

The following general picture of the relationship between propositions and states of affairs appears to be correct: The field of propositions can be divided into equivalence classes on the basis of the equivalence relation " $p$ proposes the same thing as q" (or in other words: "p represents the same state of affairs as q"); these equivalence classes correspond one-to-one to states of affairs. But has every state of affairs a non-empty class of representing propositions corresponding to it? Some states of affairs are too comprehensive for having a propositional representation in which they are not themselves mentioned; for example, this world, as a state of affairs, has no propositional representation in which this world is not mentioned. But it does have a propositional representation in which it is itself mentioned: this world, as a state of affairs, is, plausibly, identical to the state of affairs 
that this world obtains, and hence the proposition that this world obtains is a propositional representation of this world. In general, a state of affairs $\mathrm{S}$ - because it is identical to the state of affairs that $S$ obtains (note that, for this identity to hold in all cases, the name " $S$ " must always be interpreted as rigidly designating the state of affairs in question) - can always be represented by the proposition that $S$ obtains. Every state of affairs has, therefore, a non-empty class of representing propositions corresponding to it. No doubt, a propositional representation is imperfect if the represented state of affairs is itself mentioned in it, but it remains a propositional representation nonetheless.

\section{How are states of affairs related to tropes?}

Tropes are individuals (or particulars), states of affairs are not. Thus no state of affairs is a trope, and no trope a state of affairs. However, regarding their existence, tropes and states of affairs are closely related. This red, for example, exists if, and only if, the following state of affairs obtains: that the proximate bearer of this red is red. In general, we have

P2 This $F$ exists if, and only if, the proximate bearer of this $F$ is $F$,

and

P3 $x$ is $F$ if, and only if, the state of affairs that $x$ is $F$ is an obtaining state of affairs,

and therefore:

P4 This $F$ exists if, and only if, the state of affairs that the proximate bearer of this $F$ is $F$ is an obtaining state of affairs.

This needs a few comments. (1) The "is" in " $x$ is F" is of course the "is" of exemplification. (2) Since tropes are individual accidents, they need a bearer; the proximate bearer of this $F$ is that bearer of this $F$ which is not a bearer of it in virtue of anything else being a bearer of it. In the case of this 
red, the proximate bearer is likely to be a certain region of the surface of a material object; that material object is also a bearer of this red, but not the proximate one. (3) In this context, I have made use of the indexical (or demonstrative) mode of referring to tropes; however, the normal mode of referring to tropes is not via singular terms of the form this $F$, but via singular terms of the form the (so and so) $F$ of $X$ (where $X$ is the proximate bearer of the trope, and "so and so" indicates a specification of $F$ which, if necessary, makes the singular trope-referring term uniquely referring). (4) One can refer to tropes that do no longer exist and to tropes that never existed; for example, "the last smile of Peter is still well remembered by me" and "the repentance of Peter never occurred."

Does this $F$ exist because the proximate bearer of this $F$ is $F$, or is the proximate bearer of this $F F$ because this $F$ exists? P2 does not tell us how to answer this question. Nor does P4 answer the question whether a trope exists because the state of affairs that corresponds to it obtains, or whether the state of affairs that corresponds to it obtains because the trope exists. I do not believe that there is an obvious answer to these questions. But suppose that tropes were (in the sense just indicated) ontologically prior to their corresponding states of affairs, would this mean that tropes are simpliciter ontologically prior to states of affairs? It would not - since there are states of affairs that do not seem to correspond to a trope or even to a bundle of tropes (whereas of course every trope, since it has a certain state of affairs corresponding to it, in its turn corresponds to that state of affairs), for example, the states of affairs (already mentioned in Section 1) that this glass is not a glass designed by $N . N$. and that it is either a glass designed by $N^{\prime} . N^{\prime}$. or by $N^{\prime \prime}$. $N^{\prime \prime}$. Besides negative and disjunctive states of affairs, also relational states of affairs - for example, that Anne loves Peter - pose an obstacle to assuming that tropes are (simpliciter) ontologically prior to states of affairs, and therefore also to assuming that states of affairs are reducible to tropes or bundles of tropes. I, for my part, do not believe that ontological reduction can ever be a worthwhile philosophical undertaking, but if reduction must be done, then reducing tropes to states of affairs seems the more promising project, since every trope corresponds in an obvious way to a state of affairs: this $F$ to the proximate bearer of this $F$ being $F$, and the $F$ of $X$ to $X$ being $F$, where $X$ is the proximate bearer of the trope. 


\section{How are states of affairs related to facts?}

Facts are states of affairs that obtain. Hence every fact is a state of affairs. But since not every state of affairs obtains, there are states of affairs that are not facts. It is rather unfortunate that the highly useful distinction between states of affairs and facts is obliterated by the widespread practice of treating the words "fact" and "state of affairs" as synonyms.

But what does it mean that a state of affairs obtains, that it is a fact? In my view, to obtain, to be a fact, is what it means for a state of affairs to be actual. In other words, facthood, obtaining, is the actuality of states of affairs. The actuality of states of affairs can be used for defining the ontologically central concept of exemplification:

P5 $\mathrm{X}_{1}, \ldots, \mathrm{X}_{\mathrm{N}}$ exemplifies $\mathrm{R}^{\mathrm{N}}$ if, and only if, the composition of $\mathrm{R}^{\mathrm{N}}$ with $X_{1}, \ldots, X_{N}$ is an actual state of affairs (an obtaining state of affairs, $a$ fact).

Here $R^{N}$ stands for an $N$-adic universal $\left(N \geq 1\right.$; if $N=1$, then $R^{N}$ is a property; if $N \geq 2$, then $R^{N}$ is a relation). For "the composition of $R^{N}$ with $X_{1}$, $\ldots, X_{N}$ " one can briefly write " $\left[R^{N}, X_{1}, \ldots, X_{N}\right]$." The composition-manner of naming states of affairs is an ontologically more explicit manner of naming them than the "that"-manner. If $\mathrm{R}^{\mathrm{N}}$ is an $\mathrm{N}$-adic universal and $\mathrm{X}_{1}$, $\ldots, \mathrm{X}_{\mathrm{N}}$ are entities which are (in the order presented) suitable for $\mathrm{R}^{\mathrm{N}}$, then, and only then, " $\left[R{ }^{N}, X_{1}, \ldots, X_{N}\right]$ " names a state of affairs; and it names a fact if the state of affairs it names is actual. (The compositional suitability just mentioned is the basis for all type-distinctions between universals.)

Sometimes a distinction is made between exemplification and instantiation, such that, for instance, a certain red-trope instantiates redness, whereas a red apple exemplifies redness, but does not instantiate it (is not an instance of it, in contrast to the trope). The distinction between exemplification and instantiation can be captured by treating instantiation as a particular type of exemplification: instantiation is exemplification by individuals which are not substances. In view of this, the above definition of exemplification can easily be supplemented by a definition that captures the concept of instantiation - if one insists on distinguishing exemplification and instantiation. Interestingly, the need to distinguish instantiative 
and non-instantiative exemplification seems to be properly felt only in the case of the exemplification of properties.

A note on actuality: Actuality is a so-called transcendental - a transcategorial ontological concept - which, as such, applies to entities in every ontological category. In every category, however, it manifests itself differently. Facthood is its manifestation in the category of states of affairs. The conceptual relationship between existence and actuality is treated differently by different authors: some have identified existence and actuality, others have separated them. In my view, the word "existence" is used on different occasions to express different concepts, one of which is actuality.

\section{How are states of affairs related to events?}

The right question to ask on being confronted with a reference to an event which one is not acquainted with and which one wishes to know better is this: What belongs to that event? And the answer to this question must invariably be that one is presented with a temporally ordered list of states of affairs - of the states of affairs that belong to that event. (In the limiting case, the temporal order consists of only one moment in time.) This suggests that events are, basically, temporally ordered sequences of states of affairs. Sometimes not every state of affairs in a temporally ordered sequence of states of affairs can be known, and often temporally ordered sequences of states of affairs are so rich in states of affairs that it is humanly impossible to know or state all of them (by stating sentences that express propositions that represent those states of affairs). This is the source of the typical ontological non-transparency of events, which, typically, makes them like individuals: eventum (typicum) est ineffabile (cf. the well-known dictum of medieval ontology: individuum est ineffabile).

Once events are treated as temporally ordered sequences of states of affairs, there yet remains much room for further ontological questions. For example, do all states of affairs that belong to an event belong to it essentially, or do only some of those states of affairs belong to it essentially, or is it perhaps the case that all the states of affairs that belong to an event do not belong to it essentially? Are events regarding their essences homogeneous (which, for example, is the case if, for every event $E$, all the states of 
affairs that belong to $E$ belong to it essentially), or are events regarding their essences heterogeneous (which, for example, is the case if, for some event $E$, all the states of affairs that belong to $E$ belong to $E$ essentially, whereas for some other event $E^{\prime}$, some state of affairs that belongs to $E^{\prime}$ does not belong to $E^{\prime}$ essentially)? It is not the task of this paper to answer these questions, but a theory of events that treats events as temporally ordered sequences of states of affairs will have to answer them (for some efforts in this direction, see Meixner 2000 and Meixner 2004a).

\section{How are states of affairs related to truthmakers?}

Some states of affairs are truthmakers. In fact, all - and only - obtaining states of affairs are truthmakers. They make true all propositions that represent them (and, via the propositions, they make true all the sentences that may happen to express those propositions). The transmission-arm of truthmaking, so to speak, is displayed by P1 above, and more completely by

P6 A proposition $p$ is true if, and only if, some state of affairs that is represented by $p$ obtains.

Like P1, P6 is an analytic biconditional that could, it seems, be used to justify two rather different causal, or quasi-causal, consequences of itself and the assumption that $p$ is a true proposition: (1) $p$ is true because some state of affairs represented by $p$ obtains, or (2) some state of affairs represented by $p$ obtains because $p$ is true. But if "because" is to be used to introduce a causal or quasi-causal explanation (and it is only this meaning of "because" which is relevant for explicating truthmaking), then, as a matter of fact, only the first "because"-statement is acceptable. It expresses the essence of truthmaking - and one may well wonder what is so interesting about it as to justify the existence of the truthmaker-industry, by which I mean the huge amount of ontological publications that have been dedicated to the subject of truthmakers.

The reason why ontological writers are so interested in truthmakers and truthmaking seems to be that there are two restricting conditions that together define relatively narrow boundaries for the puzzle-solving activity 
they so enthusiastically engage in. The first restricting condition is that not all states of affairs are to be accepted as truthmakers - negative and disjunctive states of affairs, for example, are not to be accepted as truthmakers. Why not? - The ultimate reason for many seems to be the assumption that there simply are no such things as negative or disjunctive states of affairs. Yet, there certainly are true negative propositions, and true disjunctive propositions, among the former the highly interesting negative general-existential propositions (for example, the proposition that no pig flies). How are these propositions made true by states of affairs that are neither negative nor disjunctive? That seems to be a highly interesting question.

The second, more or less implicit restricting condition is the tendency to understand truthmaking in a truly causal, and not only quasi-causal, way. This tendency suppresses the relatively obvious sense - by making it look inadequate - in which states of affairs can be regarded as truthmakers: the sense that can be gathered from $\mathrm{P} 1$ and $\mathrm{P} 6$ above if these principles are supplemented by the specification of a quasi-causal direction that runs from states of affairs to propositions, and not vice versa. A new - truly causal sense - of truthmaking is being sought, and finding that sense seems to be a highly interesting task.

Moreover, it should not be overlooked that the deepest motivation behind the quest for truthmakers does not seem to be simply a desire of answering the question "What makes propositions true?", but rather the timehonored metaphysical desire of finding the ultimate sources of actuality which would also be what ultimately makes propositions true, i.e., the ultimate truthmakers. States of affairs, however, can hardly be the ultimate truthmakers. Though the actuality of states of affairs is the proximate source of the truth of propositions, actual states of affairs are normally not the ultimate source of that truth, since, normally, they are not the ultimate sources of their own actuality. For normally it is not the case that an obtaining state of affairs obtains - is actual - per se. (Exceptions are such states of affairs as the state of affairs that $1=1$ or the state of affairs that everything coloured is extended.) Normally, an obtaining state of affairs obtains only per alterum: there is a factmaker for it; but then, if we are to avoid an infinite regress, we must, in tracing back the line of factmakers, arrive at a state of affairs that either obtains by chance (without cause) or 
by cause of something that is not a state of affairs, perhaps God or Schopenhauer's Will, or another rational or irrational agent. Therefore, either chance or something else that is not a state of affairs is the ultimate truthmaker for every true proposition that is not made true by a state of affairs that obtains per se.

7. What are states of affairs needed for, especially non-obtaining ones?

Thus, states of affairs cannot - usually - be ultimate truthmakers, and hence, a fortiori, they usually are not needed as ultimate truthmakers. Many states of affairs, indeed, serve as proximate truthmakers, namely all states of affairs that are represented by true propositions. But if they are not the ultimate truthmakers of these propositions, their role of proximate truthmakers for them can hardly be ontologically impressive. Therefore, to rest the case for states of affairs on their truthmaking function is a very shaky matter indeed.

Moreover, only half of all states of affairs are facts and in the truthmaking business. What is the other half of states of affairs needed for? Nothing? Should we, so to speak, discard the rest, the non-obtaining states of affairs, because non-obtaining states of affairs - as long as they do not obtain - cannot be truthmakers (neither ultimate nor proximate ones)? Speaking here of discarding is metaphorical language: the literal question is, of course, whether we should assume that there are no non-obtaining states of affairs because non-obtaining states of affairs cannot be truthmakers. The straightforward answer is: we ought not to assume that there are no nonobtaining states of affairs because non-obtaining states of affairs cannot be truthmakers - since there are good reasons to assume that there are nonobtaining states of affairs, reasons which have nothing to do with truthmaking.

What are those reasons? They have already been alluded to in Section 1: states of affairs, obtaining and non-obtaining ones, are the intentional objects of various intentional attitudes. It may seem at first sight that this is not much of a reason for assuming that some entities are states of affairs indeed non-obtaining states of affairs - but on closer inspection it becomes evident that the rootedness in intentionality is all we have in any case. 
What, for example, is our reason for assuming that some entities are physical individuals? If physical individuals were not the intentional objects of various intentional attitudes of ours, we would have no reason for this. Against the attempt to capitalize on an analogy between states of affairs and physical individuals, one might object that physical individuals are much more firmly entrenched intentional objects of ours than states of affairs: that they cannot be extracted from the web of intentionality, while states of affairs can be thus extracted, especially non-obtaining ones. But this is an illusion. Let me illustrate:

Consider the moon, a physical individual. What do you (gentle reader) know about the moon? That it revolves around the earth in a period of about 28 days; that it does not revolve around its own axis; that you have often seen it in the sky; etc. Obviously, you don't know the moon without knowing a lot of facts - obtaining states of affairs - about it; obviously, you could not know the moon without knowing a lot of facts about it. Moreover, have you ever seen the moon on its own, so to speak, without its being embedded in a plethora of states of affairs that make their appearance to you at the very same time the moon does? Certainly not. But very many of those visually appearing states of affairs are in fact non-obtaining ones - and yet, it is the moon they, so to speak, represent to you - falsely, but at the same time, it is only through their false representation that you originally know of the moon at all and can begin to find out the truth about it. For example, in visual appearance it seems to you that the moon is a perfectly round disk of white light, just like the sun, only that the moon's light is not as bright as the sun's. It also seems to you that the moon is not very far away from you, that it sits for a short while on the top of yonder mountain, that it stands motionlessly in the sky, that it is bigger near the horizon and yellow, etc. All of these states of affairs do not obtain. Yet, if you extract these states of affairs from the web of intentionality, you are epistemically cut off from the moon - just about as much as a blind spider that lives in a deep cavern is epistemically cut off from it. ${ }^{2}$

\footnotetext{
${ }^{2}$ Well, not quite, for there may be other people who may tell you a lot of truths about the moon. But the knowledge you gain from them is not original. Original knowledge of and about the moon starts precisely with the visual appearing of the above-mentioned non-obtaining states of affairs and cannot be had without this appearing. Note that if nobody had any original knowledge about the moon, it would be unlikely that
} 
8. Are there negative states of affairs?

Arguing against negative states of affairs has exercised some metaphysicians to an extraordinary degree; other metaphysicians have been exercised almost as much by defending negative states of affairs. But what is a negative state of affairs? Is a state of affairs negative if, and only if, a proposition that represents the state of affairs is expressed by a negation-sentence? In that case, it will turn out that every state of affairs that is named by a singular term of the form "that $\mathrm{A}$ " is a negative state of affairs. For the state of affairs that $A$ is represented by the proposition that it is not true that non- $A$, which proposition is expressed by the negation- sentence "It is not true that non-A". Thus, the state of affairs that snow is white would turn out to be a negative state of affairs, since the proposition that it is not true that snow is not white, which represents that state of affairs, is expressed by the negation-sentence "It is not true that snow is not white".

Is it a better idea to define a negative state of affairs as a state of affairs that is a negation of some state of affairs? But then the assertion that there are no negative states of affairs would amount to the assertion that no state of affairs is a negation of any state of affairs - and there do seem to be obvious counterexamples to this latter assertion. For example, the state of affairs that 1 is larger than 2 does seem to be a negation of the state of affairs that 1 is at most as large as 2 - in the sense that the former state of affairs cannot obtain together with the latter, and that at least one of the two states of affairs must obtain. The only way out of this strait is to claim that, contrary to appearances, one of the two apparent names for states of affairs - "that 1 is larger than 2" and "that 1 is at most as large as 2" - fails to name any state of affairs. But how could one plausibly justify such a claim? (If the reader should happen to be of nominalist persuasion, he or she may consider instead of the chosen example the state of affairs that Angela Merkel is identical with George Bush and the state of affairs that Angela Merkel is different from George Bush.)

there be any knowledge at all about it. There is knowledge that is purely non-original (for example, the knowledge modern physicists have about subatomic particles), but not all knowledge can be of this kind, and knowledge about the moon, it seems to me, is not of this kind. 
As a matter of fact, one can give an argument to the conclusion that every state of affairs is a negation of some states of affairs. The argument is presented below. But here we may already take note of its conclusion. This conclusion implies that there can only be no negative states of affairs if there are no states of affairs at all - if one follows the above definition of what it is to be a negative state of affairs. But is there any other purely ontological definition of what it is to be a negative state of affairs than just that definition? (Note that we are not looking here for an epistemico-ontological definition of negative state of affairs; after all, those who defend or oppose negative states of affairs intend their discussions to deal with a purely ontological matter.) Doubtlessly, being a negation of some state of affairs is in any case a necessary condition for being a negative state of affairs (how could something be a negative state of affairs without being a negation of some state of affairs?). But what more could be required for constituting a purely ontological necessary and sufficient condition for being a negative state of affairs than just this: being a state of affairs which is a negation of some state of affairs? For my part, I don't know what more could be required.

But here is the above-announced argument to the conclusion that every state of affairs is a negation of some state of affairs: Either there are states of affairs or there are none. In the latter case, it is trivially true that every state of affairs is a negation of some state of affairs. In the former case, we turn to considering a particular kind of state of affairs: maximal-consistent states of affairs, which are defined as states of affairs that do not comprise every state of affairs, but that cannot be enlarged without comprising every state of affairs. The following principle - it can be regarded as a definition - explains the central concept involved in this definition of maximal-consistent states of affairs:

P7 A state of affairs $X$ comprises a state of affairs $Y$ if, and only if, there is a state of affairs $Z$ such that $X$ is the conjunction of $Y$ and $Z$.

Moreover, put in more precise terms, the phrase "state of affairs X cannot be enlarged without comprising every state of affairs" means just the following: there is no state of affairs $Z$ such that (1) the conjunction of the states of affairs $X$ and $Z$ is different from $X$ and (2) the conjunction of the 
states of affairs $\mathrm{X}$ and $\mathrm{Z}$ does not comprise every state of affairs. Finally, for what follows the next principle is crucial:

P8 (a) $\mathrm{MCC}(\mathrm{X})$ is the set of maximal-consistent states of affairs that comprise $\mathrm{X}$; (b) to every set $\mathrm{M}^{\prime}$ of maximal-consistent states of affairs there corresponds a state of affairs $X^{\prime}$ such that $M^{\prime}=$ $\operatorname{MCC}\left(\mathrm{X}^{\prime}\right)$.

Consider, then, any state of affairs X; consider further $\mathrm{MCC}(\mathrm{X})$ as defined by $\mathrm{P} 8$ (a). Consider, moreover, the $\mathrm{MC}$-relative complement $\mathrm{M}^{\prime}$ of $\mathrm{MCC}(\mathrm{X})$, in other words: the set of all maximal-consistent states of affairs that are not elements of $\mathrm{MCC}(\mathrm{X})$. According to $\mathrm{P} 8(\mathrm{~b}), \mathrm{M}^{\prime}=\mathrm{MCC}\left(\mathrm{X}^{\prime}\right)$, for a certain states of affairs $X^{\prime}$. Since $X$ obtains if, and only if, $X^{\prime}$ does not obtain, it is clear that $\mathrm{X}$ is a negation of $\mathrm{X}^{\prime}$ (and $\mathrm{X}^{\prime}$ a negation of $\mathrm{X}$ ).

But how does it follow that $\mathrm{X}$ obtains if, and only if, $\mathrm{X}^{\prime}$ does not obtain? For a state of affairs, to obtain means to be comprised by one particular maximal-consistent state of affairs: the world. Suppose X obtains, hence X is comprised by the world, and hence the world belongs to the set $\mathrm{MCC}(\mathrm{X})$; consequently the world does not belong to the set $\mathrm{M}^{\prime}$, and hence not to $\mathrm{MCC}\left(\mathrm{X}^{\prime}\right)$. Therefore, the world does not comprise $\mathrm{X}^{\prime}$, hence $\mathrm{X}^{\prime}$ does not obtain. Suppose, conversely, $\mathrm{X}^{\prime}$ does not obtain, hence the world does not belong to $\mathrm{MCC}\left(\mathrm{X}^{\prime}\right)$, and hence not to $\mathrm{M}^{\prime}$; consequently the world belongs to the set $\mathrm{MCC}(\mathrm{X})$ (which is the MC-relative complement of $\mathrm{M}^{\prime}$ as much as $\mathrm{M}^{\prime}$ is the $\mathrm{MC}$-relative complement of $\mathrm{MCC}(\mathrm{X})$ ), hence the world comprises $\mathrm{X}$, hence $\mathrm{X}$ obtains.

Every argument relies on premises, and every argument can, in principle, be rejected by denying or by merely not believing those premises. But if one intends the rejecting of premises as a substantial criticism of an argument - and not just as a reiteration of one's own standpoint - one should have a better reason for the rejecting of premises than simply the reason that one does not accept the conclusion of the argument. Now, the above argument really has only one premise that one might consider rejecting (the rest is logical machinery): P8(b). But is there a good reason for rejecting P8(b)? Note that, on the contrary, there is an elementary consideration that strongly suggests the truth of $\mathrm{P} 8(\mathrm{~b})$ : 
The maximal-consistent states of affairs in a set $\mathbf{M}^{\prime}$ of maximal-consistent states of affairs surely have something in common (mereologically), and if they have something in common, then they have a maximum in common: a state of affairs $X^{\prime}$ all of them comprise which is not comprised by any other state of affairs that all of them comprise. Clearly, $M^{\prime}$ is a subset of $\mathrm{MCC}\left(\mathrm{X}^{\prime}\right)$ (i.e., of the set of maximal-consistent states of affairs that comprise $\mathrm{X}^{\prime}$; see $\left.\mathrm{P8}(\mathrm{a})\right)$. And one can hardly assume that $\mathrm{MCC}\left(\mathrm{X}^{\prime}\right)$ is not also a subset of $\mathrm{M}^{\prime}$. Therefore: $\mathrm{M}^{\prime}=\mathrm{MCC}\left(\mathrm{X}^{\prime}\right)$.

Suppose one assumed that $\mathrm{MCC}\left(\mathrm{X}^{\prime}\right)$ is not a subset of $\mathrm{M}^{\prime}$, while $\mathrm{M}^{\prime}$ is known to be a subset of $\mathrm{MCC}\left(\mathrm{X}^{\prime}\right)$. As $\mathrm{X}^{\prime}$ stands to $\mathrm{M}^{\prime}$, so $\mathrm{Y}$ stands to $\mathrm{MCC}\left(\mathrm{X}^{\prime}\right)$ : $\mathrm{Y}$ is a state of affairs all the elements in $\mathrm{MCC}\left(\mathrm{X}^{\prime}\right)$ comprise and which is not comprised by any other state of affairs all of them comprise; hence, since all the elements in $\mathrm{MCC}\left(\mathrm{X}^{\prime}\right)$ comprise $\mathrm{X}^{\prime}$ (according to $\mathrm{P} 8(\mathrm{a})$ ), either $\mathrm{X}^{\prime}=\mathrm{Y}$ or $\mathrm{X}^{\prime}$ does not comprise $\mathrm{Y}$. But $\mathrm{X}^{\prime}$ comprises $\mathrm{Y}$, since $M^{\prime}$ is a subset of $\mathrm{MCC}\left(\mathrm{X}^{\prime}\right)$ (hence what all the elements in $\mathrm{M}^{\prime}$ have in common must comprise what all the elements in $\mathrm{MCC}(\mathrm{X})$ have in common). Therefore, $\mathrm{X}^{\prime}=\mathrm{Y}$. But this can't very well be, since, as has been assumed, $\mathbf{M}^{\prime}$ is a proper subset of $\mathrm{MCC}\left(\mathrm{X}^{\prime}\right)$.

\section{Are there disjunctive states of affairs?}

The principle P8(b) can also be used to show that there are disjunctive states of affairs (if there are any states of affairs at all). Suppose $X$ and $X^{\prime}$ are states of affairs. Consider $\mathrm{MCC}(\mathrm{X}) \cup \mathrm{MCC}\left(\mathrm{X}^{\prime}\right)$. Since $\mathrm{MCC}(\mathrm{X})$ and $\operatorname{MCC}\left(X^{\prime}\right)$ are each a set of maximal-consistent states of affairs, $M C C(X) \cup$ $\mathrm{MCC}\left(\mathrm{X}^{\prime}\right)$ is also such a set. Hence, according to $\mathrm{P} 8(\mathrm{~b})$, there is a state of affairs $X^{\prime \prime}$ such that $\operatorname{MCC}\left(X^{\prime \prime}\right)=\operatorname{MCC}(X) \cup \operatorname{MCC}\left(X^{\prime}\right)$. It is easy to show that $X^{\prime \prime}$ obtains if, and only if, either $X$ or $X^{\prime}$ obtains (keeping in mind that, for a state of affairs, to obtain means to be comprised by the world, which is a particular maximal-consistent state of affairs); $\mathrm{X}^{\prime \prime}$ is, therefore, a disjunction of the states of affairs $X$ and $X^{\prime}$, and hence it is a disjunctive state of affairs. 


\section{When are states of affairs identical to each other?}

To avoid confusion in answering this question, one must keep in mind that, although states of affairs and propositions can both be named by singular terms of the form "that A", states of affairs are not propositions; in particular, states of affairs are not as fine-grained as propositions (see Section 2). Indeed, there is a general way to their being more coarse-grained than propositions; that way is exhibited by the following principle:

P9 For all states of affairs $X$ and $X^{\prime}$ : if $X \neq X^{\prime}$, then $\operatorname{MCC}(X) \neq$ $\operatorname{MCC}\left(\mathrm{X}^{\prime}\right)$.

In other words: states of affairs are identical if they are comprised by the very same maximal-consistent states of affairs (making use of P8(a)). Or in other words again: states of affairs are identical if they obtain in the very same possible worlds (identifying possible worlds with maximal-consistent states of affairs, and taking to obtain in the possible world $Y$ to mean just this: to be comprised by the maximal-consistent state of affairs Y). Thus, since the state of affairs that Jack is older than Mack and the state of affairs that Mack is younger than Jack obtain in the very same possible worlds, it follows, according to P9, that they are identical. Assuming the following generalization of $\mathrm{Pl}$,

P10 For all maximal-consistent states of affairs $\mathrm{Y}$ (i.e., possible worlds $\mathrm{Y}$ ): the proposition that $A$ is true in $\mathrm{Y}$ if, and only if, the state of affairs that $A$ obtains in Y (i.e., is comprised by Y),

it follows that the proposition that Jack is older than Mack is true in the very same worlds in which the proposition that Mack is younger than Jack is true. But this does certainly not make these two propositions identical.

It is easily seen that P8 and P9 together imply that the states of affairs can be mapped one-to-one onto the sets of maximal-consistent states of affairs (i.e., onto the subsets of the set of maximal-consistent states of affairs). Since possible worlds have already been identified with maximalconsistent states of affairs, this one-to-one correspondence cannot be used to justify a reduction of states of affairs to sets of possible worlds. But cer- 
tainly it indirectly justifies those ontologists who have identified states of affairs with sets of possible worlds. There is nothing wrong with this identification, though it can seem wrong if one expects of states of affairs what one can only expect of propositions.

\section{Are there existential states of affairs?}

That I exist is an (obtaining) singular-existential state of affairs, and that there is a human being is an (obtaining) general-existential state of affairs. Hence there are existential states of affairs. And there are other devices than "that"-names for designating existential states of affairs. If "AC" designates the property of actuality, then $[\mathrm{AC}, \mathrm{X}]$, the composition of $\mathrm{AC}$ with $\mathrm{X}$ (see Section 4), is a singular-existential state of affairs, for every $\mathrm{X}$. It is another question whether all of those states are actual, i.e., whether all of them obtain.

Perhaps some readers will deny that the property of existence is identical with the property of actuality. Perhaps they will even deny that actuality might legitimately be called "existence". Then, let "IS" designate the property of being identical with something; [IS, X] - the composition of IS with $X$ - is certainly a singular-existential state of affairs, for every $X$, and this time we can also be certain that all of those states of affairs obtain (which means that every $\mathrm{X}$ exemplifies IS; see P5 in Section 4). If some readers believe that they neither refer to IS nor to AC when they use the name "the property of existence" (and use it as actually naming the (ontological) property of existence, and not just as a façon de parler), I am sorry to say that $I$ do not know what they are talking about (note that the property of being self-identical is no other property than IS).

A general-existential state of affairs, that there is an $F$, is simply the disjunction of the states of affairs [F, X], for all X; or in other words: it is the negation of the conjunction of the states of affairs [non-F, X], for all X. (The uniqueness of the result of disjunction, conjunction, and negation for states of affairs is a consequence of P8 and P9.) Thus, for example, the state of affairs that there is a flying fish is the disjunction of the states of affairs [(the property of being a) flying fish, $X]$, for all $X$. Note that [(the property of being a) flying fish, $X]$ is no other state of affairs than the state 
of affairs that $X$ is a flying fish. Hence that there is a flying fish is the disjunction of the states of affairs that $X$ is a flying fish, for all $X$. And this disjunction obtains if, and only if, the state of affairs that $\mathrm{X}$ is a flying fish obtains for some X. (For the theoretical underpinnings of all this, see my recent book, The Theory of Ontic Modalities.)

\section{Are there modal states of affairs?}

That it is possible that the sun revolves round the earth is an obtaining modal state of affairs. That it is necessary that the earth revolves round the sun is another modal state of affairs, but this time a non-obtaining one. Modal states of affairs need not be states of affairs over and above the states of affairs that were in Section 10 established to correspond one-toone to sets of maximal-consistent states of affairs. That it is possible that the sun revolves round the earth, for example, is the state of affairs [POSS, that the sun revolves round the earth], and it is ruled by the following general principle for POSS (possibility):

P11 For all states of affairs X: (a) MCC([POSS, X]) $=$ MCC if, and only if, $\operatorname{MCC}(\mathrm{X}) \neq \varnothing$; (b) $\operatorname{MCC}([\mathrm{POSS}, \mathrm{X}])=\varnothing$ if, and only if, $\operatorname{MCC}(\mathrm{X})=\varnothing$.

Here MCC is the set of (all) maximal-consistent states of affairs, $\varnothing$ the empty set, $\mathrm{MCC}(\mathrm{X})$ the set of (all) maximal-consistent states of affairs that comprise X (see Section 8). Because of the one-to-one correspondence (via the function $\mathrm{MCC}(\mathrm{X})$ ) between states of affairs and sets of maximal-consistent states of affairs, it is clear, according to P11, which state of affairs [POSS, $\mathrm{X}]$ is identical to, depending on whether $\mathrm{MCC}(\mathrm{X}) \neq \varnothing$ or $\mathrm{MCC}(\mathrm{X})$ $=\varnothing$. In the former case, it is identical to what one might call the minimal state of affairs (or the tautological state of affairs, since it is represented by any tautological proposition); in the latter case, it is identical to what one might call the maximal state of affairs (or the self-contradictory state of affairs, since it is represented by any self-contradictory proposition).

The corresponding general principle for necessity (NECS) is this: 
P12 For all states of affairs X: (a) MCC $([N E C S, X])=\mathrm{MCC}$ if, and only if, $\operatorname{MCC}(X)=\operatorname{MCC}$; (b) $\operatorname{MCC}([\operatorname{NECS}, X])=\varnothing$ if, and only if, $\operatorname{MCC}(\mathrm{X}) \neq \mathrm{MCC}$.

Clearly, according to P11 and modal intuition, MCC([POSS, that the sun revolves round the earth]) is $\mathrm{MCC}$, and therefore [POSS, that the sun revolves round the earth] obtains (since the world is an element of $\mathrm{MCC}$ ); and according to P12 and modal intuition, MCC([NECS, that the earth revolves round the sun]) is $\varnothing$, and therefore [NECS, that the earth revolves round the sun] - or in other words: that it is necessary that the earth revolves round the sun-does not obtain (since the world is not an element of $\varnothing)$.

\section{Literature $^{3}$}

Meixner, Uwe 1997: Axiomatic Formal Ontology. Dordrecht: Kluwer.

Meixner, Uwe 2000: “Essential Conceptions of Events". In: Jan Faye, Uwe Scheffler, Max Urchs (eds.), Things, Facts, and Events. Amsterdam: Rodopi, 183-193.

Meixner, Uwe 2004a: "Causation in a New Old Key". Studia Logica 76, 343-383.

Meixner, Uwe 2004b: Einführung in die Ontologie. Darmstadt: Wissenschaftliche Buchgesellschaft.

Meixner, Uwe 2006: The Theory of Ontic Modality. Heusenstamm near Frankfurt/Main: Ontos.

\footnotetext{
${ }^{3}$ The books mentioned do not only present my own detailed views on states of affairs, but, in good measure, contain explicit discussions of the views of others (notably, of the views of David Armstrong, David Lewis, and Alvin Plantinga) - something the reader may have missed in this paper.
} 